\title{
The Impact of the Rate and Variety of uses of Fixed and Mobile Broadband on the progress of CPE: A Chartered Accountant's Perspective
}

\author{
Awni Rawashdeh ${ }^{1}$, Lamia Al-namlah ${ }^{1}$ \\ ${ }^{1}$ Princess Noura bint Abdulrahman University, Arab \\ Correspondence: Awni Rawashdeh, Princess Noura bint Abdulrahman University, Arab
}

Received: April 20, 2015 Accepted: April 29, 2015 Online Published: June 5, 2015

doi:10.11114/jets.v3i4.860 URL: http://dx.doi.org/10.11114/jets.v3i4.860

\begin{abstract}
To examine the impact of the usage of fixed and mobile broadband on the progress of continuing professional education (CPE) from the perspective of chartered accountants in Saudi Arabia, an e-mail survey was conducted. A random sampling of chartered accountants in Saudi Arabia was investigated. This research was aimed to identify any correlation between the time of the day (e.g. before work, in the morning, during work, mid-day, after work, late afternoon/evening, night, late night, intermittently throughout the day) and the rate and variety of use of fixed and mobile broadband services. This research also aimed to understand the rate and variety of use of broadband services and their impact on CPE progress from the chartered accountant's perspective.
\end{abstract}

Keywords: CPE, Broadband, Use, Mobile, Chartered Accountants

\section{Introduction}

Accounting education, particularly Continuing Professional Education (CPE), has been greatly influenced by the technological revolution. At the same time, understanding and managing technology is an essential part of the professional practice of accountants. Just as accountants wish to engage with companies to improve the financial disclosure of companies, the aim of CPE is to intervene in those aspects of accounting practice that can be improved. $\mathrm{CPE}$ is a systematic attempt to facilitate change in the accountants' practice. Therefore, the main purpose of this study is to investigate the effect of the time of day and the rate and variety of broadband uses during CPE. The Saudi Organization for Certified Public Accountants (SOCPA) and other accounting organizations are interested in determining how to improve their current, continuing professional education activities. Therefore, this research offers an understanding regarding the impact of the time of the day on the rate and variety of uses of mobiles and fixed broadband connections and their impact on CPE progress and strategies at the chartered accountants' level. This is particularly useful, as there is little research published regarding the effect of the time of the day on the rate and the variety of uses of the diversity of fixed and mobile broadband usage and their impact on CPE. Greater broadband availability and usage will influence the accountants' practice in profound ways, both in the short- and long-term. The lack of recognition of a large proportion of CPE hours of online education will result in accountants losing interest in online education and deny them the knowledge of the great educational opportunities available via the Internet. Besides this, it will force accountants to use traditional education, which consumes a lot more time, in addition to the high costs incurred.

Innovation in broadband communications is the core of the developing Information Society (Lee, Marcu, \& Lee, 2011). Diffusion of the widespread broadband system and its usage contributes to the growth and productivity, attracts foreign investment (ITU, 2003, 2005), and also encourages innovation. The International Telecommunication Union (ITU) has defined broadband innovation as a network that offers a combined speed greater than or equal to $256 \mathrm{kbits}$ per second, in either one or both directions (ITU, 2005; 2006). The fixed broadband system presents an Internet service through several means, such as, cable modem, satellite, fixed wireless, leased line, WiMAX (Srinuan \& Bohlin, 2013), digital subscriber line (DSL) or a fiber-optic cable. The mobile broadband system, on the other hand, represents wireless access to a high-speed Internet through different devices like embedded modem, Universal Serial Bus (USB) dongle (Marsden, 2010) or a data card. We can define the fixed broadband system as the transmission ability with a considerable bandwidth that permits a combined provision of data, video, and voice via fixed transmission lines, such as, the cable, modem (International, 2012), and DSL. Systems like the mobile broadband innovation support data, transfer at the rate 
of 256 kbits per second, at least for all types of radio environments, which exceed the rates under second-generation wireless networks (ITU, 2006). These mobile broadband innovation systems enable several advanced video applications, such as, video mail/phone, mobile video conferencing, digital video/audio delivery, and mobile video/TV player, via wireless networks such as, WiMax, 3G, and NextG (ITU, 2006). According to the broadband penetration rate, the latest regulatory figure sets indicate an increase in the subscribers of the Saudi Broadband innovative services to 4.88 million by the end of March 2011 — an increase of 10.9\%, quarter-on-quarter, (QoQ) - from 4.4 million at the end of 2010.

Professionals account for an increasing proportion of the total workforce and they are central to the functioning of today's society (Cervero, 2000). As far as knowledge and skill go, the prerequisites for competence are changing frequently; there can be little argument with regard to the importance of maintaining professional competence and providing quality professional services. Continuing education for professionals has received a steady increase in the attention paid to it by accounting organizations over the past decades.

In line with the efforts taken to develop and enhance the accounting and auditing profession, the education and training committee in SOCPA has prepared rules organizing a continuing professional education program, which was achieved after comprehensive research on the rules adhered to in the USA and UK (SOCPA, 2013).

The broadband system has changed the way accountants are educated both inside and outside of the traditional classroom setting. Thanks to broadband, the accountants are able to access a vast amount of accounting educational content online, for CPE purposes and for personal exploration. In some cases, broadband-enabled learning has replaced the traditional accounting education entirely, as evidenced by the fact that many accountants utilize high-speed Internet connections to take classes and complete advanced degree programs and certifications online. Accountants can use broadband-enabled tools to get more individualized, interactive, and real-world learning opportunities via a variety of blended learning approaches. For example, universities are improving access to educational content by providing both free course material and traditional courses for enrolled individuals online. Similarly, SOCPA is also able to access professional development resources through the Internet to enhance their instruction, to grant the accountants an opportunity to get a high percentage of CPE hours. Section 4 provides a comprehensive survey of how fixed and mobile broadband systems are being used by accounting professionals and their impact on the progress of CPE.

Therefore, to clearly understand the advantages of the fixed and mobile broadband for each SOCPA member (chartered accountant), it is critical to know the usage of the fixed and mobile broadband of a chartered accountant. It includes the extent to which chartered accountants complete 300 CPE hours every three years, in light of the intensity and usage patterns of the technology preferences. It implies determining the rate and variety of fixed and mobile broadband innovation usage and its impact on the CPE. It may provide a variety of information regarding the impact of fixed and mobile broadband innovation on the progress of CPE. Broadband enhances access to quality accounting education via distance learning programs, online learning modules, and the availability of relevant content from any location.

Perceived lack of requirement or interest to utilize broadband innovation is assumed to be the most genuine cause why customers do not use broadband innovation (Davidson, Santorelli, \& Kamber, 2012). According to earlier studies conducted in Saudi Arabia, the argument forwarded was that the slow adoption rate of the broadband innovation service in Saudi Arabian households was for the following reasons: (i) Service quality, (ii) usefulness, (iii) usage, (iv) age of the consumer, (v) type of accommodation, and (vi) type of connection.

This reveals that a correct understanding of the effect of the usage pattern is critical for an assessment of the impact of broadband innovation. According to Dwivedi, Choudrie, \& Brinkman (2006) Internet users will act differently when they have varying, wireless, innovative broadband methods to access the Internet, because they facilitate more individualized learning, by allowing accountants to engage in activities, such as, preparing educational modules and videoconferences, which are targeted at refining or bolstering certain skills.

Hauge, Jamison, and Marcu (2010) analyzed the patterns and intensity of usage among fixed and mobile broadband customers in Portugal. From those results, it was evident that customer behavior to broadband innovation is similar across fixed and mobile users, which from the consumers' perspective, suggests that the technologies are, to some extent, substitutable, thus raising the possibility of restricted differential effects on the social goals and innovations. Some interesting results include the characteristics of Internet customers, indicated by the difference in their usage patterns and technology, reflected by their individual characteristics. The aggregate usage hours are nearly 18 hours a week for the fixed broadband and 21 hours per week for mobile broadband users. The maximum frequently reported hour count of usage for fixed broadband users is 10 hours per week (18\% of the respondents) followed by 20 hours a week (17\% of the respondents). Twenty hours per week is the most frequently reported usage of mobile broadband users, that is, $22 \%$. Mobile broadband system subscribers remain online 21 hours per week, which is longer when compared to the fixed broadband system users, with an average usage of three hours weekly; however, they utilize similar services on a frequent basis. 
Surveys reveal that usage hours and usage types are nearly consistent across regions and age groups in Portugal, even though the differences are statically significant in the econometric models. The type of usage is the same across the different access kinds. For financial applications, mobile access is slightly greater compared to the fixed access, whereas, fixed access is preferred more for news, downloading, and entertainment, including games, movies, and music. This is because the mobile broadband system attracts users with a higher income than those using fixed broadband system (Hauge, et al., 2010). According to the survey, fixed access service consumers are much more likely to become frequent broadband innovation users as compared to other access consumers. Both fixed and mobile broadband users show profiles with similar usage - between 40 and 50\% of the consumers of each access kind utilize broadband innovation many times a day - a little more than $25 \%$ use it once a day at least and less than $10 \%$ use it less than once each week.

In contrast, reports from the Australian Communication and Media Authority (ACMA) identified differences between the fixed broadband innovation and mobile broadband innovation environment with respect to the number of activities performed, as well as daily online access frequency. Different surveys that have been conducted on mobile broadband users also suggest that such consumers make many online purchases, as well as procure several different categories of products compared to fixed broadband users (ACMA, 2011).

Belo, Ferreira, and Telang (2010), examined the effects of providing broadband facilities to schools, based on the students' performances. They used a rich panel of data on broadband usage and students' grades from all the middle schools. Ceyhan (2011) indicated that the number of students that use the Internet mostly at night is notably higher than those who use it during the day. However, the Internet activities of accountants in Saudi Arabia, who use it at night, have not been sufficiently investigated. Moreover, whether the students' CPE hour levels, in different dimensions, differ according to their Internet uses at particular time zones of a day is not sufficiently clear.

Studies on these lines within Saudi Arabia are few, and are present as different user surveys examining broadband innovation adoption behavior (Hauge, et al., 2010). Although the researches mentioned above have examined the broadband innovation, none of them have investigated the effects of the pattern of use on CPE.

Furthermore, the Telecommunications Report of Saudi Arabia (2012) indicates that mobile broadband innovation penetration is likely to encourage advanced Internet applications and content usage relating to education; however, because of the current lack of data, it is difficult to support such theoretical claims.

Much has been done for the requirement of investing in broadband innovation communication infrastructure, as well as for usage promotion (LaRose, Gregg, Strover, Straubhaar, \& Carpenter, 2007). Enhanced usage of broadband innovation access services is expected to encourage the usage of advanced Internet applications and content by consumers, including chartered accountants, thereby, changing the usage pattern, increasing productivity in the existing education milieu or creating new education models. Despite the fact that data needed to prove the hypothesis will not be easy to collect, by using the reasoning mentioned above as a motivating factor, the study will progress a step closer toward a better understanding of the use of different electronic/online services in the fixed or mobile broadband innovation environment and its impact on CPE from the chartered accountants' perspective.

Hence, the goal of this study is to examine the impact of the time of the day on the rate and variety of fixed and mobile broadband uses, as well as their effectiveness in predicting CPE progress from a chartered accountant's perspective in Saudi Arabia.

The Internet adoption perspective examines the process by which the Internet can reach a critical mass of persons who will adopt. However, the impact processes cannot be understood without studying the nature and variety of the rates and uses. To complete the influence story, these need to be examined. This is especially true of CPE because of its evolving nature. This research contributes to the literature, as it examines the manner in which various factors, including the rate and variety, influence the CPE progress from the chartered accountants' perspective. It also contributes to the theory that by integrating the impact of the time of the day (e.g. mid-day, late afternoon/evening, night late, night, intermittently throughout the day) with the variety and rate of usage, besides its impact on CPE progress from the chartered accountants' perspective, the findings could contribute to the development of new CPE activities. Accordingly, the current research has developed a model. The researchers combine three factors regarding broadband usage - 'time of the day', 'variety', and 'rate of use' - to investigate their impact on CPE progress. It is expected that the model offers some motivating theoretical and practice implications for the ongoing research in this area and for the global community of accounting educators. The specific research questions in this study are as follows: (1) What time of the day does the Internet use occur? (2) Does the time of the day affect the rate and variety of use of fixed and mobile broadband innovations? (3) How is a chartered accountant's progress in a CPE program influenced by the rate and variety of innovations in fixed and mobile broadband usage?

To achieve the overall aim, we propose and test a model of CPE that can be applied to investigate the nature of impact 
that broadband usage has on the CPE progress. Having introduced this topic, the research defines the theoretical basis of this study in Section 2. In Section 3, a brief discussion on the methods utilized for research is provided. Findings are presented in Section 4. A final concluding discussion on this research is given in Section 5.

\section{Conceptual Framework and Literature Review}

Examination of the previous literature in the area of Information Systems (IS) shows that researchers have not yet studied the impact of the mobile broadband innovation in consumer usage areas from the perspective of an individual customer (Yogesh Kumar Dwivedi, et al., 2006). Rather, the maximum research has been related to broadband innovation mainly focusing on examining the factors that lead to its adoption in Saudi Arabia. Studies conducted recently highlight the need for a better understanding of the diffusion of broadband innovation, from the perspective of an individual consumer only. This limitation in studying the impact of the actual use has resulted in the lack of a correct conceptual model that is specific to the broadband innovation in Saudi Arabia. Prior studies on the adoption, pursued the line of reasoning that constructing a conceptual model particular to the mobile broadband innovation usage from the perspective of the individual consumer necessitates identification, integration, and a review of the relevant factors associated with the use of the technology that had previously been examined in the information system (IS) studies. This section, therefore, first reviews, as well as assesses, the appropriateness of the earlier technology usage models, including the factors for studying the use of mobile broadband innovation. This section next offers further theoretical justification for the choice of factors that are utilized in studying the mobile broadband innovation usage, for formulating hypotheses, and ultimately drawing the conceptual model for using broadband innovation.

\subsection{Usage Studies}

\subsubsection{Time of the Day}

The fixed and mobile broadband techniques strongly depend on understanding the users' needs, which is, however, a non-trivial task. Users' needs and interests can change over time and can depend on external contextual factors, such as, the time of usage (Golder \& Huberman, 2006). For example, the time of the day might be important for some people, but not so important for others (Yuan, Sivrikaya, Marx, \& Hopfgartner, 2014). As far as we know, a detailed analysis of the impact the time of the day on the rate and variety of use of the fixed and mobile broadband has not yet been carried out.

Korgen, Odell, \& Schumacher (2001) found time of the day to be an important influencing factor in determining Internet use. This study also shows a connection between study habits and Internet use. Students who dedicate more hours per week for study also spend more hours online than those who devote less time to their academic pursuits. In general, with increased Internet use, it is logical that students who allocate less time for studies will spend fewer hours per week on Internet use, especially for educational purposes, than their classmates who study more (Korgen, et al., 2001).

Likewise, fixed and mobile broadband services offer tremendous advantages and convenient methods to the users, to encourage them to access the Internet from any location, at any time of the day. It also gives customers greater control over managing their own time, as they can easily continue their online education and other purposes at any convenient time of the day. In view of the advantages that fixed and mobile broadband services offer, it would thus be expected that chartered accountants, who perceive fixed and mobile broadband as advantageous, would also likely to experience its effect on their CPE progress. According to Vitalari, Venkatesh, and Gronhaug, (1985) time becomes a key variable for understanding the impact of Information and Communications Technology (ICT) from the users' perspective. This is because the total available time is limited and distributed throughout the day and the time of the day of fixed and mobile broadband usage is likely to influence the rate and variety of use for other activities. Vitalari et al. (1985) suggest that the use of a new innovation directly reorganizes user 149ehaviour. Although the time of the day is expected to affect the daily life of fixed and mobile broadband users, research that focuses on the impact of the time of the day and the rate and variety of use of the fixed and mobile broadband has not been undertaken. This was the motivating reason for including this variable in this research. This leads to the hypotheses given below:

H1: Time of the day will exert a significant effect on the rate of use.

H2: Time of the day will have a significant effect on the variety of use.

Usage is another topic of interest in the IS area, besides being pertinent to the research. The studies in this particular area have been done in the form of user surveys, which have reported the 149ehaviour of broadband innovation users, as compared with the narrowband users. The results from these surveys show that Internet users behave in different ways when they are exposed to several broadband innovations. Broadband innovations in the vein of accessing internet on the mobile system helps netizens utilize the online facilities on a longer-term basis, make use of more applications or services, and apply them more often compared to the fixed system (Yogesh Kumar Dwivedi \& Weerakkody, 2007). 
Maximum broadband innovation users give a convincing rating to their online experience. When compared with the fixed broadband innovation users, mobile broadband innovation users are spending more time on electronic media applications like online music. According to the surveys conducted on broadband innovation users, it is suggested that such users make more purchases online and procure many varied categories of items when compared with fixed broadband users (International, 2012). Although the studies mentioned here examine innovations in broadband usage, they do not have theoretical underpinnings, because the data leads them and they are exploratory in nature. Understanding the impact of the pattern of usage of mobile broadband innovation on CPE from the perspective of the chartered accountants in Saudi Arabia still remains an unexplored area in the previous studies.

\subsubsection{Usage Model}

The Use Diffusion (UD) model (Shih \& Venkatesh, 2004) was created for investigating technology usage in the household context. This model suggests that constructs like rate and variety of use are vital to understanding the intensity of usage and typology of users (Shih \& Venkatesh, 2004). As this research also focuses on technology usage in the household, constructs such as rate and variety of use are considered relevant for determining the broadband innovation usage. Such research that postulates the behavior of the adoption of fixed and mobile broadband innovation will determine the following: Internet usage rate, that is, total time invested online, as well as Internet access frequency, and usage variety, that is, the count of the online activities performed.

Previous literature reveals that potential users have higher education levels, for example, college graduates are more likely to use new innovations (Rogers, 1995). Venkatesh et al. (2000) suggested a positive correlation between education level and new innovation usage. They found that individuals with good education use computers more than the less educated ones. Past research (Choudrie \& Lee, 2004) on broadband adoption has also identified a significant correlation between education and broadband adoption. Anderson et al. (2002) found that users with secondary or tertiary education were more likely to have Internet access. From the earlier discussion, it is suggested that education can be considered as an important variable that can be affected with fixed and mobile broadband usage. This is because fixed and mobile broadband is considered to be useful for continuing the educational purposes and performing CPE-related tasks. Therefore, it is expected that chartered accountants working toward the attainment of CPE are more likely to adjust the rate and diversity of their broadband use in order to achieve this goal.

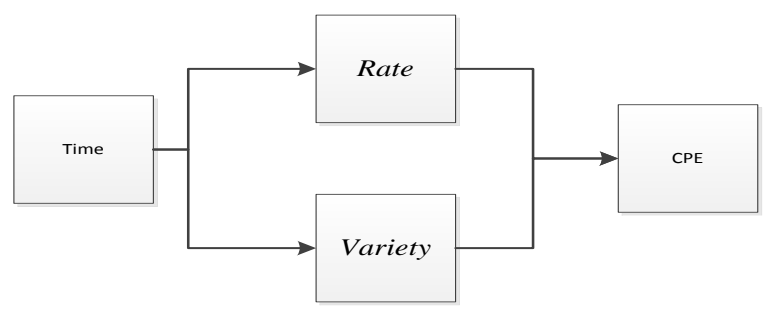

Figure 1. CPE Model

On the basis of the aforementioned discussion, the conceptual model proposed using such a research, considered $C P E$ progress as the dependent variable and the rate and variety in the use of fixed and mobile broadband innovations as the independent variables. The independent variables, namely, rate and variety of use were expected to affect the CPE progress. Going by the previous studies on technology use (Shih \& Venkatesh, 2004) the researcher postulates the hypotheses on the use of mobile broadband innovation, as given herewith:

\section{H4: Rate of use will have a significant effect on the CPE progress.}

H5: Variety of use will have a significant effect on the CPE progress.

\section{Research Approach}

As the research object in this study is comprised of chartered accountants in Saudi Arabia, it can easily be argued that an approach via an e-mail survey is the most appropriate approach for the research. This is because of issues like time, accessibility, cost, and convenience (Rawashdeh \& Selamat, 2013; Wright, 2005). The maximum limit to which researchers can be part of the context that is being studied is a vital factor that determines the research approach. In the accounting context, it is difficult for the researchers to become part of the context; hence, a survey approach is considered, which seems much more feasible when compared to others like ethnography, observations, and case studies. In this case, the selection of the approach is also influenced by the type of models and the theory employed for examining the research related to mobile broadband innovation usage. The conceptual model is expected to include several research hypotheses that are required to be tested prior to concluding the study. It requires collecting statistical analysis data and quantitative data for testing the research hypotheses. Although several research approaches are 
available within the quantitative, positivist research category, a survey is the only appropriate research approach that one can employ for conducting such researches (this refers to that which needs validation of the hypotheses and testing of the conceptual model) in social settings; in this situation, it is the accountants. Moreover, the aim of this research is to examine the mobile broadband innovation usage among the Saudi Arabian chartered accountants, which is a nationwide perspective. Therefore, to acquire a complete picture of the research issue, data collection from a huge number of chartered accountants from different parts of Saudi Arabia becomes essential. This means that using any other approach like ethnography (which makes use of observations or interview-like tools for data collection) demand extensive manpower, financial resources, and time. As this is an exploratory research project, all three factors are restricted and this limits the ability of the researcher in using them in the research investigation. Among the planned contributions of the study, one can provide insights into the Internet service providers regarding factors that are salient for adopters of fixed and mobile broadband innovations and for establishing relationships between factors such as actual usage and adoption. To achieve this, quantitative data on several variables such as demographics and performing regression analysis, are essential to illustrate this relationship. It is another logical reason to adopt a quantitative approach through collating data and surveys, which can assist the ISPs to understand the chartered accountants' behavior as well as their demographic characteristics for encouraging and promoting the adoption of mobile broadband innovation.

The survey instrument used in this study was a researcher-designed questionnaire. The items used were developed based on an in-depth review of the related literature, of which three specific articles were especially useful. One article by Dwivedi et al. (2014), dealt with the broadband adoption and usage behavior of Malaysian chartered accountants. The second article by Faulk (2009), addressed the impact of continuing professional education on the developing members' skills and competencies required for organizational success. The last article presented by Korgen, et al. (2001), addressed Internet usage among college students. From these surveys, the researcher collected items that dealt specifically with the value perceived and adjusted them to reflect the accounting profession. Additional items that the researcher felt would address the objectives in the study were incorporated into the questionnaire including the impact of the usage of fixed and mobile broadband on CPE progress, as well as the impact of the time of the day on the Internet use, besides the demographics specific to certified Accountants.

Quantitative data had to be collected from the Saudi Chartered Accountants. To collect empirical data from a target population, a self-administered questionnaire through the e-mail was considered as the most appropriate method. The main reasons for using a self-administered questionnaire included: The comparatively low cost for administration; the ability to address issues of information reliability by eliminating and reducing differences in the manner in which questions are asked (Cornford \& Smithson, 1996); accomplishment with very few facilities; access to widely dispersed samples; ample time for respondents to provide thoughtful answers; assistance offered with complex response categories or asking lengthy questions; allows asking similar repeated questions; and respondents' answers are kept confidential without the interviewers being informed of the answers. The collated data would be analyzed using the AMOS 20 and SPSS version 17.0. The chartered accountants in the Kingdom of Saudi Arabia (KSA) were the target population for this study, where continuing professional education is a prerequisite for maintaining their licenses. The accessible population was defined as licensed chartered accountants holding a current "active" status membership in the Saudi Organization for Certified Public Accountants (SOCPA). This population included approximately 697 members. The population frame was identified through the current membership roster of the SOCPA. An "active" membership in the SOCPA included only those certified accountants, who had been certified by the SOCPA. The sample drawn and used in this study was a 100\% sample of the defined accessible population. Therefore, it was found that for this research purpose, it was appropriate to employ the list of the SOCPA as a sampling frame, including stratified random sampling, as the basis for the sample selection and mail ids, and e-mailing the questionnaire, which was the data-collection tool. A detailed explanation for such a selection has been provided earlier in the text.

\section{Empirical Findings}

\subsection{Profile of Respondents}

A statistical elaboration of the sample was done. The gender distribution of the survey respondents was $97.6 \%$ male (as most of SOCPA members are men). 
Table 1. Profile of Respondents

\begin{tabular}{llll}
\hline & A & Frequency & Percent $\%$ \\
\hline \multirow{4}{*}{ Age } & $22-30$ & 47 & 28.1 \\
& $31-39$ & 69 & 41.3 \\
& $40-48$ & 34 & 20.4 \\
& Over 48 & 17 & 10.2 \\
& Total & 167 & 100.0 \\
& 5 years or less & 132 & 79.0 \\
& 10 years or less & 18 & 10.8 \\
& 15 years or less & 6 & 3.6 \\
& 20 years or less & 1 & .6 \\
& Over 21 years & 10 & 6 \\
& Total & 167 & 100.0 \\
& Degree & 99 & 59.3 \\
& Postgraduate Taught $(\mathrm{MA}, \mathrm{MSc})$ & 66 & 39.50 \\
& Postgraduate Research (PhD) & 2 & 1.20 \\
& Total & 167 & 100.00 \\
\hline
\end{tabular}

\subsection{Time of the Day with Rate of Use}

Regression analysis was conducted with the rate of use (ROU) as the dependent variable and time of the day (TOD) as the predictor variable. Regression analysis was used to predict a continuous dependent variable from a number of continuous independent variables.

From the total number of 308 cases analyzed, a significant model emerged $(\mathrm{F}(1,167)=240.294, p<.001)$. The adjusted R squared was 0.589 (Table 2). The relation was found to be significant (Table 4). It included time of the day as $(\beta=.769, p<.001)$. The findings revealed that the time of the day was correlated with the rate of use. This implied that more the variety in the time of the day, the higher the chances were that the chartered accountants would utilize more hours on the Internet. However, it was important to indicate that because the adjusted R squared was acceptable (Table 2) and the time of the day was almost able to explain the variation in the rate of use.

Table 2. Model Summary

\begin{tabular}{llllc}
\hline Model & R & R Square & Adjusted R Square & Std. Error of the Estimate \\
\hline 1 & $.769^{\text {a }}$ & .591 & .589 & 1.01551
\end{tabular}

a. Predictors: (Constant), Time of the day

b. Dependent Variable: Rate of Use

Table 3. ANOVAb

\begin{tabular}{llllll}
\hline Model & Sum of Squares & df & Mean Square & F & Sig. \\
\hline Regression & 247.805 & 1 & 247.805 & 240.294 & $.000^{\mathrm{a}}$ \\
Residual & 171.189 & 166 & 1.031 & & \\
Total & 418.994 & 167 & & & \\
\hline
\end{tabular}

a. Predictors: (Constant), Time of the day

b. Dependent Variable: Rate of Use

Table 4. Coefficientsa

\begin{tabular}{llllll}
\hline & \multicolumn{5}{c}{ Unstandardized Coefficients Standardized Coefficients } \\
\cline { 2 - 5 } Model & $\mathrm{B}$ & Std. Error & Beta & $\mathrm{t}$ & Sig. \\
\hline 1 (Constant) & -.008 & .195 & & -.041 & .967 \\
Time of the day & .791 & .051 & .769 & 15.501 & .000 \\
a. Dependent Variable: Rate of Use & & & \\
\hline
\end{tabular}

\subsection{Time of the Day with a Variety of Use and CPE}

The dependent variable, which measures the variety of use (VOA), is categorical (discrete) in nature and represented by Social Media, Entertainment, Research/Education, Continuing Professional Education (CPE), Video conferencing/Online lectures, Downloading, Shopping and News. If the dependent variable is categorical (discrete), then logistic regression should be used. Therefore, logistic regression analysis was performed with variety of use as the dependent variable and time of the day as the predictor variable. A total of 167 cases were analyzed and the whole model was considered significantly reliable $(\quad(6, N=168)=201.382, p<.001)$ (Table 5). This model accounted for between 69.8 and $71.9 \%$ of the variance in variety of use (Table 6), and $67.9 \%$ of the broadband adopters were successfully predicted. Table 8 lists the coefficients, Wald statistics, associated degrees of freedom, and probability 
values for each of the predictor variables. This shows that only the mid-day, late afternoon/evening, night, and late night and intermittently and throughout the day, reliably predicted broadband adoption.

Table 5. Model Fitting Information

Table 6. Pseudo R-Square

\begin{tabular}{lllcc}
\hline Model & Model Fitting Criteria & Likelihood Ratio Tests & \\
\cline { 2 - 5 } & -2 Log Likelihood & Chi-Square & df & Sig. \\
\hline Intercept Only & 401.264 & & & \\
Final & 199.882 & 201.382 & 6 & .000 \\
\hline
\end{tabular}

Table 7. Likelihood Ratio Tests

\begin{tabular}{ll}
\hline Cox and Snell & .698 \\
Nagelkerke & .719 \\
McFadden & .335 \\
\hline
\end{tabular}

\begin{tabular}{lllll}
\hline Effect & Model Fitting Criteria & Likelihood Ratio Tests & & \\
& -2 Log Likelihood of Reduced Model & Chi-Square & df & Sig. \\
\hline Intercept & 375.821 & 175.939 & 6 & .000 \\
tod & 401.264 & 201.382 & 6 & .000 \\
\hline
\end{tabular}

The chi-square statistic is the difference in -2 log-likelihoods between the final model and a reduced model. The reduced model is formed by omitting an effect from the final model. The null hypothesis is that all parameters of that effect are 0 .

Table 8. Parameter Estimates

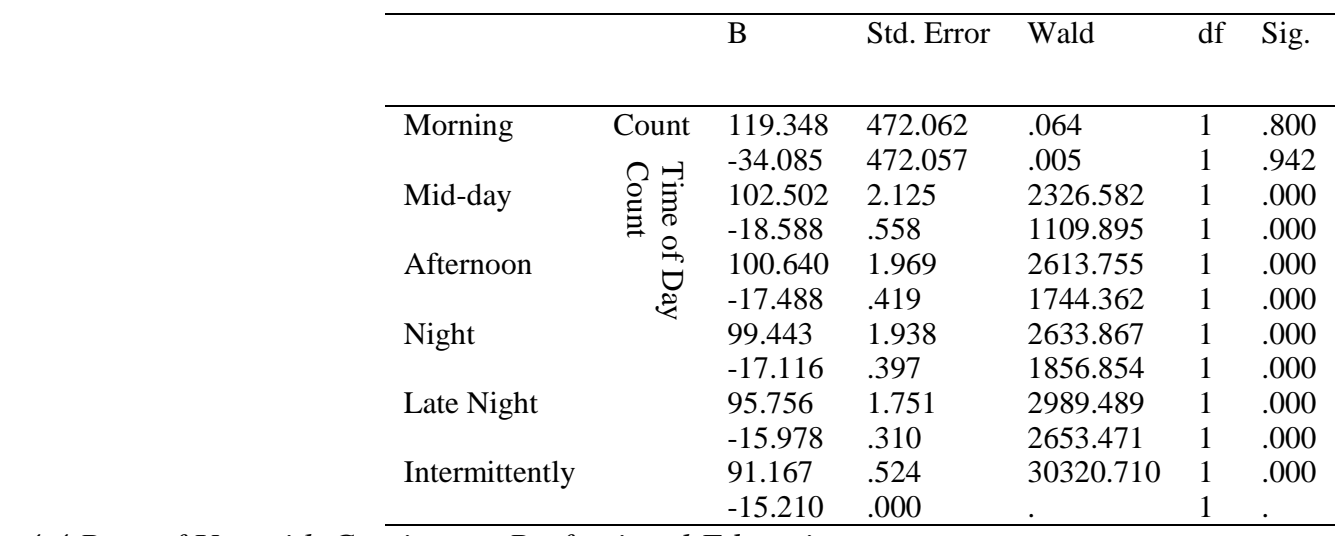

\subsection{Rate of Use with Continuous Professional Education}

Regression analysis was performed with Continuous Professional Education (CPE) as the dependent variable and rate of use as the predictor variable. Regression analysis was used to predict a continuous dependent variable from a number of continuous independent variables. A total of 167 cases were analyzed. From the analysis, a significant model emerged $(\mathrm{F}(1,167)=283.435, p<.001)$. The adjusted $\mathrm{R}$ squared was 0.628 (Table 9). The relation was found to be significant (Table 11) and included the rate of use $(\beta=.794, p<.001)$. The time of the day was correlated with continuous professional education, which meant that the higher the rate of use, the higher the chances were that the chartered accountants would achieve more hours of continuous professional education.

Table 9. Model Summary

\begin{tabular}{lcccc}
\hline Model & R & R Square & Adjusted R Square & Std. Error of the Estimate \\
\hline 1 & $.794^{\mathrm{a}}$ & .631 & .628 & 1.18501 \\
\hline
\end{tabular}

a. Predictors: (Constant), rate5

b. Dependent Variable: CPE

Table 10. ANOVAb

\begin{tabular}{lllllll}
\hline \multicolumn{2}{l}{ Model } & Sum of Squares & df & Mean Square & F & Sig. \\
\hline 1 & Regression & 398.013 & 1 & 398.013 & 283.435 & $.000^{\mathrm{a}}$ \\
& Residual & 233.106 & 166 & 1.404 & & \\
& Total & 631.119 & 167 & & & \\
\hline
\end{tabular}

a. Predictors: (Constant), rate5

b. Dependent Variable: CPE 
Table 11. Coefficients

\begin{tabular}{clllll}
\hline & \multicolumn{2}{l}{ Unstandardized Coefficients } & \multicolumn{2}{l}{ Standardized Coefficients } & \\
Model & $\mathrm{B}$ & Std. Error & Beta & $\mathrm{t}$ & Sig. \\
\hline 1 (Constant) & 1.445 & .184 & & 7.858 & .000 \\
rate5 & .975 & .058 & .794 & 16.836 & .000 \\
\hline
\end{tabular}

a. Dependent Variable: CPE

\subsection{Variety of Use with Continuous Professional Education}

A new scale has been created for Variety of Use. Categorical variables require special attention in regression analysis because, unlike dichotomous or continuous variables, they cannot be entered into the regression equation just as they are. Categorical variables need to be recoded into a series of variables and only then can be they entered into the regression model. Therefore, simple regression coding is used. Regression analysis is used when an interval dependent variable from a number of categorical independent variables is to be predicted. When using regression for contrasts, we first need to create new variables and use these new variables as predictors in the regression model. The purpose is to conduct a regression analysis with Continuous Professional Education as the dependent variable and the Variety of Use as the predictor variable. A total of 168 cases have been analyzed.

From the analysis, once again a significant model emerged $(\mathrm{F}(3,167)=67.418, p<.001)$ (Table 13). The adjusted $\mathrm{R}$ squared was 0.705 (Table 12). The results obtained from this test suggested that a significant correlation existed between the Variety of Internet Use and Continuous Professional Education. Only two variables were found to be positively correlated, as shown in Table 14. These included the Continuing Professional Education (CPE) ( $\beta=.178, p$ $<.001)$ and video conferencing/online lectures $(\beta=.119 ; p=.011)$. For example, rate of Internet use was positively correlated with Continuous Professional Education, which meant that the higher the use of Internet or video conferencing / online lectures for Continuous Professional Education purposes, the higher the chances that the chartered accountant would achieve more hours of CPE. Even as Use of the Internet for other purposes did not focus on CPE, it would lead to a shortage in the number of hours of CPE completed during the year.

Table 12. Model Summary

\begin{tabular}{lllll}
\hline Model & R & R Square & Adjusted R Square & Std. Error of the Estimate \\
\hline 1 & $.846^{\mathrm{a}}$ & .715 & .705 & 1.05642 \\
\hline
\end{tabular}

a. Predictors: (Constant), x7, x2, x1, x6, x4, x3

Table 13. ANOVA ${ }^{\mathrm{b}}$

\begin{tabular}{lllllr}
\hline Model & Sum of Squares & df & Mean Square & F & Sig. \\
\hline 1 Regression & 451.440 & 6 & 75.240 & 67.418 & $.000^{\mathrm{a}}$ \\
Residual & 179.679 & 161 & 1.116 & & \\
Total & 631.119 & 167 & & & \\
\hline
\end{tabular}

a. Predictors: (Constant), x1, x2, x3, , x4, x6, x7

b. Dependent Variable: CPE

Table 14. Coefficients

\begin{tabular}{|c|c|c|c|c|c|c|}
\hline \multirow{2}{*}{\multicolumn{2}{|c|}{ Model }} & \multirow{3}{*}{$\begin{array}{l}\text { Unstandardized Coefficients } \\
\text { B } \\
4.210\end{array}$} & \multicolumn{2}{|c|}{ Standardized Coefficients } & \multirow[t]{2}{*}{$\mathrm{t}$} & \multirow[t]{2}{*}{ Sig. } \\
\hline & & & Std. Error & Beta & & \\
\hline & (Constant) & & .091 & & 46.347 & .000 \\
\hline $\mathrm{x} 1$ & Social Media & -4.269 & .302 & -.647 & -14.136 & .000 \\
\hline $\mathrm{x} 2$ & Entertainment & -3.269 & .318 & -.466 & -10.278 & .000 \\
\hline $\mathrm{x} 3$ & Communications & -2.269 & .240 & -.454 & -9.466 & .000 \\
\hline $\mathrm{x} 4$ & Research/Education & -1.131 & .245 & -.221 & -4.621 & .000 \\
\hline x6 & Professional Education & .731 & .283 & .119 & 2.580 & .011 \\
\hline $\begin{array}{l}\mathrm{x} 7 \\
\text { a. } \mathrm{D}\end{array}$ & $\begin{array}{l}\text { Video conferencing/ Online lectures } \\
\text { apendent Variable: CPE }\end{array}$ & 1.731 & .425 & .178 & 4.069 & .000 \\
\hline
\end{tabular}

\section{Discussion}

A total of four research hypotheses were tested to examine whether the independent variables significantly explained the dependent variables. All the research hypotheses were supported by the data, which means that all the variables significantly explained the chartered accountants' CPE progress.

\subsection{Time of the Day}

As discussed earlier (Section 2.1) the time of the day is positively correlated with the rate of use; after which the users are likely to select a suitable time to use the Internet (A Aykut Ceyhan, 2008). Following this idea, it was assumed that 
the rate of use is positive for their CPE progress. This theoretical assumption is confirmed by the findings obtained in this research, which suggest that the rate of use has a significant positive influence on the CPE progress (Fig. 1).

\subsection{Rate of Use}

Following the theoretical basis presented in Section 2.1, this research categorized the rate of use into eight levels, which were expected to provide measures of broadband use. The fourth level was expected to predict if the CPE progress was due to the intensity of the rate of use. The outcomes obtained from this study regarding the CPE progress revealed that CPE progress is affected by the intensity of the rate of use. This indicates that chartered accountants use the fixed and mobile broadband to achieve more CPE points through their focus on variety of use.

Several previous empirical studies have found that the time of the day is an important factor for determining the variety of use (Ceyhan, 2008). Compared to the fixed broadband, the mobile broadband offers an "always-on" access to the Internet, anytime and anywhere, and provides several advantages, particularly convenience and satisfaction to its users.

\subsection{Variety of Use}

It was expected that the variety of use would also probably affect the CPE progress. The greater the focus on specific services among the chartered accountants, the more likely it was that the CPE progress increased. Previous research suggested that student performance was affected by Internet use (A Aykut Ceyhan, 2008). The chartered accountants were also aware of the benefits from the type of Internet use for their CPE progress, which was essential to enhance their progress. This was considered to be one of the factors that accelerated the CPE progress by the chartered accountants in Saudi Arabia. On other hand, the findings obtained in this study also confirmed that some types of use (e.g., Social Media) had a significantly negative influence on the CPE progress. The greater the focus on non-related services (e.g., Social Media, Entertainment, Communications and Research/Education) to CPE, the more likely it was that the CPE progress would decrease (Table 14). This is in line with the argument that the majority of users is already aware of what to do with the Internet, as it permeates people's lives and work environments (Oh et al., 2003). This may be one possible reason why the variety of use was a positive as well as a negative influence on some of the Internet services for CPE progress.

\section{Conclusions}

The findings revealed that the rate and variety of use of the mobile and fixed broadband were good predictors of the CPE progress, which was in line with the arguments presented in the theoretical section (Rogers, 1995; Vitalari et al., 1985). Furthermore, it was seen that time of the day was a good predictor of the rate and variety of use, which in turn affected the CPE progress.

The importance of the online accounting information to accountant professional development is growing rapidly. Accountants can access the information intermittently throughout the day, late afternoon/evening, night and all day. Access to online continuing accounting education must be immediate, relevant, credible, and easy to use. A sense of high utility demands content that is focused and well indexed. The roles of the CPE provider must be reshaped to include helping accountants seek and construct the kind of knowledge they need to improve accounting practices to serve their customers.

Therefore, this study recommends a result of the evolution of the Internet to increase the number of informal hours, in order to help the chartered accountants achieve the largest number of points, to reduce the time spent on the CPE and focus on the audit work. This plays an important role in the operation of the economic system and has the primary responsibility of assuring the users that the financial statements are free from material misstatements. The study suggests a mechanism which can be used to verify the actual practice of the chartered accountants' Continuing Professional Education (CPE). SOCPA's electronic site can put an interface of the chartered accountants, containing important links by which they can access the learning links and thus the system will be able to document the Continuing Education Process electronically. The findings also reveal that the SOCPA officials should ensure that every chartered accountant has at least some Internet access through the SOCPA website by using the appropriate software and resources to document his/her online CPE. As fixed and mobile broadband systems enable a range of Internet services, individuals studying in Saudi Arabia or in this case, the chartered accountants, add one more perspective to the understanding of the impact of the use of fixed and mobile broadband on CPE progress in developing countries.

\subsection{Directions for Further Research}

Thus, this research presents one of the initial efforts toward understanding the implications of fixed and mobile broadband usage for chartered accountants, outside of the context of the developed countries. The findings are specifically useful for policy makers in SOCPA, as specified above. Factors that are reported significant are important and require attention in order to encourage further CPE progress for the chartered accountants. Further, the number of formal CPE points high so that informal CPE can be used as a replacement for formal CPE. Although this study has its 
limitations, such as the generalization of these findings to the whole of Saudi Arabia and the inability to supplement the questionnaire data with interviews or adopt a longitudinal approach to data collection, due to time and resource constraints, these limitations cannot be overcome. For instance, future research of a similar nature may entail a longer data collection period, which will subsequently eliminate any variables that may have produced anomalies in the results.

\section{References}

Anderson, B., Gale, C., Jones, M., \& McWilliam, A. (2002). Domesticating broadband—what consumers really do with flat-rate, always-on and fast Internet access. BT Technology Journal, 20(1), 103-114. http://dx.doi.org/10.1023/A:1014578227619

Arabia, T. R. $\quad$ o. $\quad$ S. (2012). Saudi Arabia Telecommunications Report. http://ae.zawya.com/researchreports/p_2010_01_19_12_47_05/20120216_p_2010_01_19_12_47_05_034429.pdf

Belo, R., Ferreira, P., \& Telang, R. (2010). The effects of broadband in schools: Evidence from Portugal. Available at SSRN 1636584.

Cervero, R. M. (2000). Trends and issues in continuing professional education. New Directions for Adult and Continuing Education, 2000(86), 3-12. http://dx.doi.org/10.1002/ace.8601

Ceyhan, A. A. (2008). Predictors of problematic Internet use on Turkish university students. CyberPsychology \& Behavior, 11(3), 363-366. http://dx.doi.org/10.1089/cpb.2007.0112

Ceyhan, A. A. (2011). University Students' Problematic Internet Use and Communication Skills According to the Internet Use Purposes. Educational Sciences: Theory and Practice, 11(1), 69-77.

Choudrie, J., \& Lee, H. (2004). Broadband development in South Korea: institutional and cultural factors. European Journal of Information Systems, 13(2), 103-114. http://dx.doi.org/10.1057/palgrave.ejis.3000494

Cornford, T., \& Smithson, S. (1996). Project Research in Information Systems Macmillian. London.

Davidson, C. M., Santorelli, M. J., \& Kamber, T. (2012). Toward an inclusive measure of broadband adoption. International Journal of Communication, 6(0), 2555-2575.

Dwivedi, Y. K., \& Weerakkody, V. (2007). Examining the factors affecting the adoption of broadband in the Kingdom of Saudi Arabia. Electronic Government, An International Journal, 4(1), 43-58.

Dwivedi, Y. K., Choudrie, J., \& Brinkman, W.-P. (2006). Consumer usage of broadband in British households. International Journal of Services and Standards, 2(4), 400-416. http://dx.doi.org/10.1504/IJSS.2006.010472

Dwivedi, Y. K., Tamilmani, K., Williams, M. D., \& Lal, B. (2014). Adoption of M-commerce: examining factors affecting intention and behaviour of Indian consumers. International Journal of Indian Culture and Business Management, 8(3), 345-360. http://dx.doi.org/10.1504/IJICBM.2014.060365

Faulk, M. (2009). Continuing Professional Education: A Practical Ideal Type Model and the Program Assessment of a Federal Office of Inspector General. Texas State University-San Marcos.

Golder, S. A., \& Huberman, B. A. (2006). Usage patterns of collaborative tagging systems. Journal of information science, 32(2), 198-208. http://dx.doi.org/10.1177/0165551506062337

Hauge, J. A., Jamison, M. A., \& Marcu, M. I. (2010). Consumer Usage of Broadband Internet Services: an analysis of the case of Portugal. Adoption, Usage, and Global Impact of Broadband Technologies: Diffusion, Practice, and Policy, 198.

ITU. (2003). Promoting broadband: Background paper for workshop on promoting broadband. http://www.itu.int

ITU. (2005). Promoting broadband: Background paper for workshop on promoting broadband. http://www.itu.int.

ITU. (2006). Promoting broadband: Background paper for workshop on promoting broadband. http://www.itu.int.

Korgen, K., Odell, P., \& Schumacher, P. (2001). Internet use among college students: Are there differences by race/ethnicity. Electronic Journal of Sociology, 5(3).

Kuicheu, N. C., Fotso, L. P., \& Siewe, F. (2007). Iconic communication system by XML language:(SCILX). Paper presented at the Proceedings of the 2007 international cross-disciplinary conference on Web accessibility (W4A).

LaRose, R., Gregg, J. L., Strover, S., Straubhaar, J., \& Carpenter, S. (2007). Closing the rural broadband gap: Promoting adoption of the Internet in rural America. Telecommunications Policy, 31(6), 359-373. http://dx.doi.org/10.1016/j.telpol.2007.04.004

Lee, S., Marcu, M., \& Lee, S. (2011). An empirical analysis of fixed and mobile broadband diffusion. Information Economics and Policy, 23(3), 227-233. http://dx.doi.org/10.1016/j.infoecopol.2011.05.001 
Marsden, C. (2010). European law and regulation of mobile net neutrality. European Journal of Law and Technology, $1(2)$.

Rawashdeh, A., \& Selamat, M. H. (2013). Critical Success Factors Relating to the Adoption of XBRL in Saudi Arabia. Journal of International Technology and Information Management, 22(2), 4.

Rogers, E. M. (1995). Diffusion of Innovations: modifications of a model for telecommunications Die Diffusion von Innovationen in der Telekommunikation (pp. 25-38): Springer. http://dx.doi.org/10.1007/978-3-642-79868-9_2

Shih, C.-F., \& Venkatesh, A. (2004). Beyond adoption: Development and application of a use-diffusion model. Journal of Marketing, 68(1), 59-72. http://dx.doi.org/10.1509/jmkg.68.1.59.24029

Srinuan, C., \& Bohlin, E. (2013). Analysis of fixed broadband access and use in Thailand: Drivers and barriers. Telecommunications Policy, 37(8), 615-625. http://dx.doi.org/10.1016/j.telpol.2013.03.006

Vitalari, N. P., Venkatesh, A., \& Gronhaug, K. (1985). Computing in the home: shifts in the time allocation patterns of households. Communications of the ACM, 28(5), 512-522. http://dx.doi.org/10.1145/3532.3537

Wright, K. B. (2005). Researching Internet - based populations: Advantages and disadvantages of online survey research, online questionnaire authoring software packages, and web survey services. Journal of Computer Mediated Communication, 10(3), 00-00.

Yuan, J., Sivrikaya, F., Marx, S., \& Hopfgartner, F. (2014). When to Recommend What? A Study on the Role of Contextual Factors in IP-based TV Services. Paper presented at the MindTheGap@ iConference.

\section{$(\mathrm{oc}) \mathrm{BY}$}

This work is licensed under a Creative Commons Attribution 3.0 License. 